\title{
VIVÊNCIA TECNOLÓGICA NA EDUCAÇÃO BÁSICA: UMA ESTRATÉGIA PARA O ENSINO E APRENDIZAGEM DE PROFESSORES E ALUNOS
}

\author{
VIVENCIA TECNOLÓGICA EN LA EDUCACIÓN BÁSICA: UNA ESTRATEGIA \\ PARA LA ENSEÑANZA Y APRENDIZAJE DE PROFESORES Y ALUMNOS
}

\author{
TECHNOLOGICAL EXPERIENCE IN BASIC EDUCATION: A TEACHING- \\ LEARNING STRATEGY FOR TEACHERS AND STUDENTS
}

\author{
Giseli S. LUCAS ${ }^{1}$ \\ Maria Iolanda MONTEIRO2
}

RESUMO: O objetivo deste artigo é discutir se as aulas de Vivência Tecnológica, ministradas aos alunos do Ensino Fundamental I, da rede do Serviço Social da Indústria de São Paulo SESI/SP, é uma estratégia pedagógica que auxilia os docentes no processo de ensino e aprendizagem e os alunos na autonomia digital. É notória a tendência do uso cada vez mais frequente de computadores e outras tecnologias na educação escolar; por este motivo, a Vivência Tecnológica foi implantada na rede para potencializar os aspectos didáticos e metodológicos para o ensino e aprendizagem. Por essa razão, esta pesquisa objetiva analisar a dinâmica deste momento de "Vivência Tecnológica", que recebe o subsídio da teoria construtivista e contribuições de duas profissionais, e verificar se as aulas no Laboratório de Informática e as montagens e programações no Laboratório de Ciências e Tecnologias, com os recursos de blocos de montagem, contribuem para uma abordagem metodológica de ensino relacionada ao desenvolvimento do pensar, do raciocinar, da resolução de problemas, das práticas de leitura e escrita. E ainda, verificar se esta estratégia pode ser referenciada como estratégia pedagógica significativa. A pesquisa buscou o entendimento das relações entre as duas profissionais, identificando a articulação entre o material de ensino, as aulas de informática e as aulas regulares na sala de aula do primeiro ano. Este trabalho possibilitou o aprofundamento das características utilizadas, avaliando a qualidade da relação e socialização entre estas duas esferas formativas para o aluno do primeiro ano do ensino fundamental, identificando os procedimentos metodológicos, e, ainda, investigando a profissionalização dos agentes educacionais, assim como sua formação.

PALAVRAS-CHAVE: Vivência tecnologia. Autonomia digital. Metodologias de ensino.

RESUMEN: El objetivo de este artículo es discutir si las clases de Vivencia Tecnológica, impartidas a los alumnos de la Enseñanza Fundamental I, de la red del Servicio Social de la Industria de São Paulo SESI / SP, es una estrategia pedagógica que auxilia a los docentes en el proceso de enseñanza y aprendizaje y Los alumnos en

${ }^{1}$ Universidade Estadual de Campinas (Unicamp), Campinas - SP - Brasil. Doutoranda em Educação GEPEC. E-mail: giselilucas@ hotmail.com.

${ }^{2}$ Universidade Federal de São Caros (Ufscar), São Carlos - SP - Brasil. Professora Doutora Titular. Email: iolanda.uab@gmail.com. 
la autonomía digital. Es notable la tendencia del uso cada vez más frecuente de computadoras y otras tecnologías en la educación escolar. Por ello, la Vivencia Tecnológica fue implantada en la red para potenciar los aspectos didácticos y metodológicos para la enseñanza y el aprendizaje. Por esta razón, esta investigación objetiva analizar la dinámica de este momento de "Vivencia Tecnológica", que recibe el subsidio de la teoría constructivista y contribuciones de dos profesionales, y verificar si las clases en el Laboratorio de Informática y los montajes y programaciones en el Laboratorio de Ciencias y Tecnologías Con los recursos de bloques de montaje, contribuyen a un abordaje metodológico de enseñanza relacionado al desarrollo del pensamiento, del razonamiento, de la resolución de problemas, de las prácticas de lectura y escritura. A la vez, se busca comprender si puede la referida estrategia servir como acción pedagógica significativa. La investigación buscó el entendimiento de las relaciones entre las dos profesionales, identificando la articulación entre el material de enseñanza, las clases informáticas y las clases regulares en el aula del primer año. Este trabajo posibilitó la profundización de las características utilizadas, evaluando la calidad de la relación y socialización entre estas dos esferas formativas para el alumno del primer año de la enseñanza fundamental, identificando los procedimientos metodológicos y aún, investigando la profesionalización de los agentes educativos así como su formación.

PALABRAS-CLAVE: La tecnología de la tecnología. Autonomía digital. Metodologías de enseñanza.

ABSTRACT: This article presents a discussion about Technological Experience classes in Elementary School of the São Paulo Industry Social Service network (SESI / SP) as a pedagogical strategy to assist teachers in the teaching and learning process and students in digital autonomy. The trend towards the increasing use of computers and other technologies at school is well-known. For this reason, the Technological Experience was implemented in the network to enhance the didactic and methodological aspects of teaching and learning. This research aims to analyze the dynamics of the "Technological Experience", based on the constructivist theory with contributions of two professionals. The proposal is to verify if classes in Computer Laboratories, involving assembly and programming, contribute to teaching as a pedagogical approach to develop thinking, reasoning, problem solving, reading and writing practices. Thus we can understand the relationship between the two professionals, by identifying the articulation among courseware, computer classes and regular classes in the first grade. This study promoted the deepening of the characteristics used, by evaluating the quality of the relationship and socialization between these two spheres of education and their methodological procedures and also by investigating educational agent professionalization and training.

KEYWORDS: Technological Experience. Digital autonomy. Teaching methodologies.

\section{Introdução}

Apresentamos neste texto uma reflexão teórica e prática da Vivência Tecnológica, desenvolvida na pesquisa de mestrado intitulada "Vivências Tecnológicas 
da Rede SESI-SP: uma estratégia organizacional do processo de ensino $\mathrm{e}$ aprendizagem", no Programa de Pós-Graduação em Educação da Universidade Federal de São Carlos (UFSCar), em 2014. Procuramos discutir nesta pesquisa se os momentos de Vivência Tecnológica (VT), ministrados aos alunos do primeiro ano do Ensino Fundamental I, de uma rede de escolas particulares da Indústria do Estado de São Paulo, é uma estratégia capaz de auxiliar os discentes na sua aprendizagem e autonomia digital e os docentes como recurso e estratégia metodológica de ensino.

Como objetivo geral, analisamos a dinâmica deste momento de "Vivência Tecnológica" e verificamos se as aulas no Laboratório de Informática e das montagens e programações no Laboratório de Ciências e Tecnologias, com os blocos de montagem ${ }^{3}$, escopo da vivência tecnológica, contribuem para o processo de escolarização dos alunos, auxiliando-os no desenvolvimento do pensar, do raciocinar e na resolução de problemas.

Como objetivo específico, buscamos o entendimento das atuações das duas profissionais, responsáveis pela Vivência Tecnológica, a analista de informática e a professora alfabetizadora (docente do primeiro ano do Ensino Fundamental I).

A intenção foi buscar o aprofundamento das metodologias utilizadas, avaliando a qualidade da relação entre estas duas esferas formativas em benefício do aluno e da formação continuada das profissionais envolvidas, visto que as professoras possuem formações distintas e exercem funções complementares no trato com a disciplina Vivência Tecnológica (VT).

\section{Teoria e metodologia da pesquisa}

Esta pesquisa supõe a estreita relação entre pesquisador e objeto de estudo, no aspecto do problema. Por esse motivo, utilizamos da abordagem qualitativa para orientá-lo, que "envolve a obtenção de dados descritivos, obtidos no contato direto do pesquisador com a situação estudada" (LUDKE, 2012 p. 13). Acreditamos que a abordagem qualitativa nos remete a um caráter mais social da pesquisa, assim apresentaremos um levantamento de dados, informações e discussões em um estudo de caso que, segundo Menga e Ludke (2012), mesmo com similaridades a outros estudos, carrega em si muita distinção e um caráter único e particular. O estudo de caso foi o

\footnotetext{
${ }^{3}$ Blocos de Montagem são peças que se encaixam e são utilizadas para a construção de projetos
} 
procedimento metodológico adotado para estudar profundamente o tema, detalhando e ampliando o conhecimento para compreender melhor o problema.

Com base nos instrumentos de entrevistas e observações das aulas de duas professoras, atuantes no primeiro ano do ensino fundamental, sendo uma professora regente de turma e uma professora analista de informática, ambas da mesma unidade, localizada em cidade do interior do estado de São Paulo, delimitamos o campo de investigação do estudo.

A Vivência Tecnológica, disciplina com conteúdo interdisciplinar, ministrada aos alunos do primeiro ano, foi escolhida como momento privilegiado para investigação. A observação desta aula demonstrará a interação das duas profissionais, assim como se esta disciplina contribui para a escolarização dos alunos de 6 anos do primeiro ano do ensino fundamental, e, ainda, investigar como se dá a preparação profissional das professoras envolvidas.

A coleta e análise de dados obtidos nas entrevistas e observações realizadas foi a segunda etapa da pesquisa, e se deu através da delimitação clara dos objetivos e sistematização dos instrumentos de coleta, que no caso desta pesquisa foi a organização do questionário e do relatório de observação (diário de campo), seleção dos sujeitos e análise das informações coletadas. Em seguida, na discussão dos resultados obtidos, realizamos a articulação entre a teoria e a realidade descrita pelos dados com base nos objetivos da pesquisa.

Por fim, na conclusão das análises, sistematizamos os resultados da pesquisa, apontado a resposta aos objetivos propostos e, principalmente, a contribuição desta pesquisa para o desenvolvimento de práticas, metodologias de ensino e aprendizagem e construção de conhecimentos acerca da Vivência Tecnológica (VT).

\section{Campo da pesquisa e contextualização do currículo}

A pesquisa se deu em uma instituição de abrangência nacional que encontra-se em todos os estados do território brasileiro. É um órgão privado que se mantém através da Federação das Indústrias de cada estado. A regional de São Paulo é um departamento ligado à Federação das Indústrias do Estado de São Paulo (FIESP). A rede tem 67 anos (1945-2013) dedicados à educação, principalmente, a Educação Básica, segmentada em educação infantil, ensino fundamental e médio. 
É importante delinear o campo em que estão assentadas as concepções de homem, sociedade e conhecimento adotadas pela Instituição em seu currículo, e descrever de forma sucinta as relações entre a sociedade e a Indústria.

\section{Concepções de homem e mundo}

O Serviço Social da Indústria surgiu no Brasil de um projeto social e político, visando contribuir para a melhoria de vida do país e para o aperfeiçoamento do espírito de solidariedade entre as classes no contexto de 1946, período pós-guerra, marcado pela transição de uma economia agrária para uma industrial, elevada taxa de natalidade, migrações, imigrações e um sistema escolar pouco expandido (SESI, 2003, p. 5).

O diferencial que apontamos desta organização curricular e que é objeto desta pesquisa, é quanto à parte diversificada do currículo, pois é possível verificar que os conteúdos visam atender a uma clientela e alguns objetivos institucionais que abordam a prática, a vivência e a interdisciplinaridade. Para isso faz-se uso de uma nomenclatura diferenciada para nomear estes componentes com uma conotação bem prática vivência.

Segundo os referenciais de ensino da rede (SESI, 2010), na parte diversificada do currículo, oferece-se momentos de: Orientação de estudos; Vivências Esportivas; Vivência de Língua Estrangeira; Vivências Artísticas; Vivências de Ciências e Tecnologia; Vivência de Língua estrangeira moderna-inglês e Vivência de empreendedorismo.

Entende-se dessa forma que as Diretrizes para Educação Integral em Tempo Integral (SESI, 2010) tem uma proposta diferenciada e uma organização didática e curricular que leva em consideração alguns fatores que otimizam os tempos e espaços escolares, a saber:

\footnotetext{
-A realização da Orientação de estudos de $1^{\circ}$ ao $5^{\circ}$ ano, no período da manhã, e do ensino fundamental II, no período da tarde;

-A possibilidade de propor aulas duplas, de modo que possam se desenvolvidas com maior tranquilidade evitando prejuízo de tempo com deslocamentos dos estudantes;

-A utilização da Biblioteca Escolar, do laboratório de Informática e da Sala de Ciências e Tecnologia como espaços de aprendizagem diferenciados da sala de aula para a ampliação do trabalho desenvolvido com as expectativas de ensino aprendizagem;

-A organização em um único período (manhã ou tarde) das aulas dos componentes curriculares da base nacional comum nas unidades escolares em que haja professores com jornada de trabalho parcial, do $1^{\circ}$ ao $5^{\circ}$ ano.

-A realização da Discussão Pedagógica Coletiva (DPC);
} 
-A necessidade de aquisição de jogos educativos, aparelhos de som, materiais esportivos e didáticos, entre outros.(SESI, 2013, p. 12).

Acreditamos que a parte diversificada do currículo é a oportunidade de ampliar, favorecer e enriquecer com experiências adquiridas no meio social ou do grupo pertencente aos estudantes, e é através dos momentos de vivências que os alunos podem experimentar, vivenciar na prática, as atividades que serão de grande utilidade em suas vidas, e é com esta oportunidade que a rede procura proporcionar aos seus estudantes momentos que reflitam os anseios da comunidade industrial e se diferenciam quanto às aprendizagens ofertadas. Para isso, se faz necessário que o fazer docente seja sempre objeto de reflexão e de ação.

\section{Vivências Tecnológicas - características e especificidades de uma metodologia e de uma formação}

As vivências, como mencionado, pertencem à parte diversificada do currículo e compõem a base de conhecimento do aluno; entende-se, principalmente, que a vivência tecnológica caminha junta com a ciência e tecnologia, e se caracteriza pelos momentos onde os alunos desenvolvem conteúdos de linguagens, matemática, ciências humanas e ciências da natureza com subsídio ora dos computadores e softwares ora pelos blocos de montagem.

As transformações econômicas mundiais, políticas públicas e a sociedade são as maiores incentivadoras deste desenvolvimento, assim julgamos ser muito importante trazer algumas discussões para dentro dessa pesquisa, como, por exemplo, a noção de avanço tecnológico, tão pungente nestes tempos.

O avanço tecnológico que, na concepção mais geral, nada mais é do que o renovar das ciências e/ou de suas técnicas, tem influenciado no papel da educação. E a educação, por sua vez, deve disponibilizar o acesso, não a tudo que se produz a título de avanço tecnológico, mas às habilidades e competências que tornam possível se apropriar do que há de novo e desnaturalizar que a tecnologia não influencia o estado da educação, assim como afirma Silva, Melo, Bock e Chrispino, se acreditamos:

[...] que a tecnologia é neutra é negligenciar o atual estado miserável da humanidade. Um estado ideal no qual os cidadãos possam alcançar armas eficientes, é diferente de medicamentos eficientes, que são diferentes de educação eficiente. Ética e socialmente não podemos ignorar essas diferenças. (2015, p. 214) 
Contudo, é importante diferenciar, neste momento, informação de conhecimento científico. Ter acesso à informação está muito facilitado ultimamente, pois ela está ao alcance das pessoas, em vários meios (rádio, TV, internet, bibliotecas), assim como afirma BOGHI et al:

As pessoas estudam para ampliar seus campos ou domínios conceituais bem como as relações entre conceitos. Ocorre que na aprendizagem, quando a forma de ensinar se aproximada daquilo que os alunos já conhecem, essa aprendizagem torna-se facilitada. (2016, p. 23)

O conhecimento científico, no entanto, requer orientação e investigação. Assim, destaca-se o papel fundamental das escolas para preparar alunos e professores para enfrentarem grandes desafios.

A Vivência de Ciência e Tecnologia, segundo as Diretrizes do Tempo Integral da rede (SESI, 2010), tem o papel de ultrapassar a aprendizagem de conceitos e teorias e relacionar os conteúdos estanques com práticas formativas, mais dinâmicas e simuladoras da vida real, de forma que o aluno possa compreender, experimentar e criar. Deve-se levar em consideração o saber humano historicamente construído, embora seja importante trazer para a realidade de cada aluno os recursos que possam ser aplicados e estudados. A rede, por sua vez, no exercício de seu papel social, procura através dessa vivência específica, aprofundar nos recursos que a ciência e a tecnologia podem proporcionar aos alunos.

Entretanto, para que isso aconteça, dentro da modalidade da Educação Integral em Tempo Integral (SESI, 2010), busca-se a todo o momento a integração do uso dos recursos tecnológicos com as expectativas de ensino e aprendizagem, os conteúdos do currículo e a formação docente.

As Diretrizes da Educação em Tempo Integral da rede orientam que nas atividades planejadas pelos professores sejam sempre realizadas observado o planejamento, a ludicidade e a criatividade. Para isso, os temas devem estar no planejamento didático do docente. As vivências precisam, ainda, considerar os recursos dos blocos de montagem, os recursos do LIE e da lousa digital como situações que o apoiarão no objetivo maior que são as expectativas de ensino e aprendizagem.

Espera-se que a Vivência Tecnológica, também, cumpra um papel motivador no processo de descoberta e interesse pela inovação, fazendo uma analogia com a construção de projetos e blocos de montagem. Busca-se, ainda, construir uma geração de novos estudantes, capazes de apropriar-se desses conhecimentos e aplicá-los na vida. Esta filosofia permeia toda a política de inserção tecnológica observada. 


\section{Formação docente continuada para uma vivência tecnológica}

Com base nas demandas descritas acima e, ainda, constantes nos objetivos da Vivência Tecnológica e do currículo da rede, o professor da sala e o analista de suporte em informática devem se preparar e planejar as atividades a serem desenvolvidas pelos alunos.

Esta preparação se dá nos momentos dedicados ao planejamento. As duas profissionais elaboram o roteiro a ser seguido com as necessidades identificadas nas observações realizadas em sala de aula. É importante observar que o trabalho da analista está a serviço das expectativas de ensino e aprendizagem elegidos pela professora alfabetizadora. Dessa forma, a analista expõe todas as possibilidades de interação com os recursos disponíveis e juntas as professoras decidem as melhores estratégias para colocar o planejamento em prática.

Principalmente para os primeiros anos no ensino fundamental, onde as atividades requerem muitos cuidados devido à especificidade da turma, a interação professor e analista de suporte em informática deve ser ainda maior. Construir uma identidade para esses momentos de Vivência Tecnológica requer convencer os alunos que estes momentos, apesar de lúdicos, fazem parte da aula, de forma que se deve construir um conhecimento ao final do projeto montado, usando os blocos de montagem, e das atividades realizadas nos computadores no laboratório de informática educativa.

Nesta perspectiva, para que as atividades sejam realizadas e bem trabalhadas, a comunicação entre os profissionais envolvidos deve ser bem sincronizada, além do conhecimento entre as esferas formativas (analista de informática e professora alfabetizadora) procurar ser compartilhados, discutidos e até ensinados mutuamente.

Com relação aos alunos do primeiro ano, em particular, deve-se oportunizar momentos para aproximar os conteúdos tecnológicos das práticas de alfabetização e letramento. A responsabilidade da analista de informática é estar atento às possibilidades de integração de dois momentos: a sala de aula regular e as vivências tecnológicas (SESI, 2003).

No que diz respeito aos momentos de vivências tecnológicas observou-se, principalmente, que os professores são exigidos para atuarem como motivadores do uso dos recursos tecnológico, dessa forma a interação entre a analista e a professora é um momento de estudo e aprendizado para ambas; a primeira se apropria dos 
conhecimentos pedagógicos; e a segunda, dos conhecimentos tecnológicos e informacionais.

A influência dos recursos na alfabetização e no letramento dos alunos do primeiro ano do ensino fundamental tem como referência um grande nome da pesquisa tecnológica em educação, o pesquisador Seymour Papert, matemático e entusiasta do uso das tecnologias para o ensino, que influenciado por outro grande pesquisador, Jean Piaget, desenvolveu um pensamento que nomeou como construcionismo; são sobre estas bases que se apoiam os estudos para a formação das profissionais envolvidas.

Observamos que estas referências permitem ao professor, aluno e material de suporte didático aprofundar, desenvolver e incorporar algumas capacidades e competências que só são possíveis em uma filosofia que entende a necessidade de motivação, preparação e organização dos estudos, do professor e do aluno.

O recurso mediador utilizado para se desenvolver estas competências, habilidades e capacidades é entendido, nesta proposta, como sendo a educação tecnológica. Sob estes parâmetros estão construídas as orientações para as aulas com recursos dos blocos de montagem. $\mathrm{O}$ desenvolvimento das atividades não se resume apenas na construção de algum projeto e, sim, em um processo que contempla a motivação, o desenvolvimento, a dúvida, as conclusões e novas dúvidas, tudo isso mediado pelos recursos dos blocos de montagem, professor, analista, fascículos e softwares.

Estas considerações são importantes porque, para atingir os objetivos dessa primeira fase, professores e alunos têm muitos desafios, principalmente, fazer das aulas momentos dinâmicos e atrativos e que deem conta da complexidade das crianças e das infâncias.

No atual contexto, fala-se muito em variados tipos de linguagem e tipos de letramento e alfabetização (SOARES, 2002); o fato é que estas possibilidades de alfabetização e letramento intensificam e privilegiam a aprendizagem, possibilitando fazer uso de um leque de estratégias que contemple as múltiplas formas de inserção no mundo letrado. Entende-se por esta afirmação a necessidade de diversificar as formas de abordar o conteúdo, assim como contemplar novos conteúdos nas nossas práticas. Portanto, é possível observar que os profissionais envolvidos neste processo estão realizando a alfabetização tecnológica dos professores (SAMPAIO, LEITE; 2013)

Este tipo de formação não é acabado, assim como qualquer outro tipo de conhecimento: não se esgota, e sim, se transforma. É uma realidade em constante 
mutação, e segundo Sampaio e Leite (2013), a alfabetização tecnológica de professores “estão também em constante aperfeiçoamento e diversificação e devem ser lidas crítica e permanentemente por professores e alunos, da mesma forma que o mundo em geral" (p. 52).

Professores e alunos têm as metas a cumprir no primeiro ano, que são as descritas no fazer pedagógico (SESI, 2010), e para atingi-las lançam mão de uma série de estratégias para construir estes saberes, sempre tendo em vista que o conteúdo seja meio para atingir um fim maior, que é desenvolver capacidades e habilidades.

Transportando as metas para a prática da Vivência Tecnológica, consideraremos as atividades desenvolvidas pela analista de informática (diferencial desta proposta) no auxílio à professora alfabetizadora. Assim, descreveremos a participação dessa profissional junto à professora do primeiro ano em prol da alfabetização.

$\mathrm{O}$ analista de suporte em informática é o profissional indicado para fazer a mediação na tríade professor - aluno - recurso tecnológico. Orientar, esclarecer dúvidas e articular os aplicativos da informática à ação docente, auxiliando os professores nos processos de planejamento e gestão do ensino e aos alunos na utilização dos equipamentos e de seus recursos: estas funções estão descritas no perfil deste profissional (SESI, 2010a, p. 45).

As aulas de Vivência Tecnológica (VT) são um verdadeiro momento articulador para promoção e o desenvolvimento da educação tecnológica e, ainda, um processo de autoformação, visto que não foi possível abordar na formação inicial dos profissionais envolvidos um conteúdo de tecnologia educacional. Para entender melhor como é a relação dessas duas profissionais, realizaram-se algumas entrevistas que favoreceram o entendimento e evidenciaram a articulação dessas duas esferas formativas. A seguir um trecho da entrevista onde se evidencia a relação e autoformação:

\footnotetext{
A nossa relação é ótima e ao contrário da coordenadora estamos em contato diário seja nos intervalos do café ou nas aulas de VT, com uma certa antecedência sempre planejamos qual a melhor maneira de transpor o conteúdo que desejo dar para o LIE, nos recursos utilizados ela me acompanha para poder melhor orientar os alunos e ajudá-los nas suas dificuldades. (ENTREVISTADA, Analista de Informática).
}

E, ainda, para a professora observada, a apropriação e o encantamento com as atividades ficaram claras em suas palavras. Quando questionada sobre suas impressões das aulas de VT ela diz que "para mim é vivenciar, experimentar, sentir, praticar usá-la a nosso favor" (ENTREVISTADA, Professora Alfabetizadora). 
Entender as concepções das profissionais envolvidas faz parte do processo de aprendizagem; dessa forma, descrevemos como é o entendimento sobre o assunto.

\section{Percepções e concepções do que é uma Vivência Tecnológica}

Pensando sobre a prática da Vivência Tecnológica como recurso tecnológico a serviço de uma metodologia que procura colocar o aluno como protagonista e autônomo e, ainda, pretende fazer com que professores e alunos sejam colaboradores, entendemos que cabe ao professor mediar o processo de aprendizagem e ao aluno fazer as relações entre a problematização e contexto apresentado, para enfim, o aprendizado acontecer. Segue um trecho da entrevista da analista de informática que exemplifica a prática pedagógica:

\footnotetext{
Nas capacitações que recebemos ficou bem claro que essa nova estratégia era para ser o mais prático possível. $\mathrm{O}$ aluno deve ser o que cria, desenvolve e põe a mão na massa literalmente. Então entendemos o termo como a experiência vivida e que torne o contato com o conteúdo o mais significativo possível. Acredito que tem dado certo, pois, os alunos saem comentando a atividade e mesmo passado algum tempo eles ainda se lembram. (ENTREVISTADA Professora alfabetizadora).
}

Para auxiliar no processo de alfabetização as profissionais envolvidas fazem uso de diversos métodos e estratégias, inclusive tecnológicas, aqui entendidas como as definidas por "processos e produtos relacionados com os conhecimentos provenientes da eletrônica, da microeletrônica e das telecomunicações" (KENSKI, 2007, p. 25), para conseguir desenvolver nos alunos as capacidades linguísticas de ler e escrever, falar e ouvir, já que pode parecer natural, mas não acontecem espontaneamente, devem ser ensinadas.

O entendimento das aulas de VT está articulado com o entendimento do uso das Tecnologias de Comunicação e Informação (TIC) de Belloni (2009), ou seja, as TIC nas escolas são de fundamental importância, porque estas ferramentas estão presentes na vida de toda criança e adolescente e funcionam na socialização. Assim deveria refletir, diretamente, no processo educativo, já que faz parte da sociedade contemporânea e provoca mudanças em todas as escalas, sejam elas sociais, políticas ou econômicas. Esta conceituação é importante para contextualizar o cenário que encontramos. 
Nesta perspectiva é necessário que os procedimentos educacionais desenvolvam uma lógica de pensamento tecnológico, necessário para efetivamente ter um diferencial de oferta do uso dos recursos da Vivência Tecnológica.

Ainda, segundo Belloni,

Também é preciso ressaltar que as mídias são importantes e sofisticados dispositivos técnicos de comunicação que atuam em muitas esferas da vida social, não apenas com funções efetivas de controle social (político, ideológico...), mas também gerando novos modos de perceber a realidade, de aprender, de produzir e difundir conhecimentos e informações. (2009, p. 1083).

A literatura aponta (BELLONI, 2009; KENSKI, 2007; LÉVY 1993) que a maioria das mediações realizadas com computadores e outros apetrechos tecnológicos com acesso à internet garante, talvez, o acesso à informação, mas não confirma a aquisição de conhecimento científico. Nestas condições é necessário buscar subsídios que superem a aprendizagem apenas de conceitos e teorias, relacionadas com conteúdos abstratos, para um ensino que faça uso de ferramentas do cotidiano dos alunos e que proporcione uma melhor compreensão e aplicação dos conteúdos ministrados.

$\mathrm{Na}$ organização da aprendizagem, tanto de professores, quanto de alunos, devese levar em conta o fato que as tecnologias são resultado do saber humano e nestas condições devem ser exploradas e usadas de tal forma que integrem as experiências dentro da escola, proporcionando aos estudantes a ampliação de seus conhecimentos. Assim, os alunos do primeiro ano foram escolhidos porque este é o ano quando as aulas de Vivência Tecnológica são iniciadas e o uso rotineiro e planejado são aplicados.

\section{Considerações finais}

As especificidades da rede, primeiro quanto ao tempo do aluno na escola, pelo menos 9 horas diárias, distribuídas no intervalo de 7 horas da manhã até às 16 horas da tarde, fazem com que espaços escolares, tempos, práticas docentes, suportes e estruturas, recursos e contingente humano se mobilizem para garantir a permanência dos alunos na escola com qualidade no ensino oferecido e segurança física e de apoio. Os profissionais que trabalham nesta jornada, devem ter garantidos o seu bem-estar para que o trabalho possa ser realizado da melhor forma possível e, ainda, poder contar com suporte e recurso para viabilizar a prática. 
Dessa forma, os conteúdos escolares foram dinamizados de tal forma que as aulas ou vivências se integrem e possam ser compartilhadas por todos os agentes educacionais. As rotinas dos alunos têm carga horária maior devido ao tempo na escola e, pensando sob este ponto de vista, é essencial que cada momento passado na escola seja muito bem estudado e se coloque a serviço do ensino e da aprendizagem.

Um currículo aplicado, ao que a rede autodenomina "ensino integral em tempo integral", deve buscar, então, a integralidade de formação dos discentes e, consequentemente, a interdisciplinaridade dos conteúdos a serem ministrados. Este entendimento é o que justifica a proposta de reunir dois profissionais para ministrarem juntos a Vivência Tecnológica.

O tempo escolar, como apontado anteriormente, garante a inserção no currículo de momentos que favoreçam o encontro destes profissionais. Apontamos essa característica por considerar esta oportunidade um diferencial que mostra uma visão institucional voltada para a integração.

Uma segunda característica peculiar do currículo da rede para o primeiro ano do ensino fundamental é adotar momentos de Vivência Tecnológica, além de outras modalidades de vivência, abarcadas no programa da rede, porque, diante do uso das tecnologias, há outras possibilidades de alfabetizar e letrar.

Este entendimento está claro, através da documentação que orienta a prática do analista de suporte em informática, que se dá através de auxiliar, esclarecer, assistir e orientar professores, alunos e funcionários na correta utilização dos equipamentos e recursos propondo estratégias, programas e abordagens, com o uso do laboratório de ciência e tecnologia e laboratório de informática educativa.

Esta afirmação é importante, pois demonstra duas preocupações, primeiro, que o analista de suporte em informática deve dedicar-se ao serviço de pensar sobre como ajudar e apoiar alunos e professores do primeiro ano, dentro dos objetivos propostos, fazendo uso dos recursos disponibilizados. Segundo, entende-se que o professor de sala de aula, alfabetizador, necessita de ajuda quanto ao uso dos recursos tecnológicos.

A relação dos objetivos do primeiro ano de Vivência Tecnológica deve levar em conta, ainda, o perfil discente, a estrutura e os recursos disponíveis conforme SESI (2010), fatores que tornam imprescindíveis momentos de discussão e planejamento entre as duas esferas formativas, momento único e rico em estratégias e apropriação do conteúdo por parte da professora de sala de aula e uma experiência pedagógica formativa para a analista de suporte em informática. 
Podemos apontar, com base nesta investigação, que estes recursos dos blocos de montagem contribuem não somente de forma a estimular tátil e visualmente os alunos, mas, principalmente, agregam valores que alteram a forma de pensar e interagir socialmente. É possível afirmar com base nestes recursos metodológicos que podemos contar com tecnologias além da oralidade, da escrita ou da impressão. O conhecimento por simulação, por exemplo, método principal da vivência tecnológica, é uma estratégia eficiente neste sentido. Simular a realidade fornece subsídios reais para que os alunos ponham em prática o que aprenderam e melhor aproximam os discentes do conteúdo que interagem com os recursos testando possibilidades.

As possibilidades de uso dos recursos pedagógicos estão bastante claras no material escrito e nas atuações das duas profissionais, que se propõem a trabalhar com a Vivência Tecnológica (VT). A resposta a nossa questão de investigação principal: os momentos denominados de Vivência Tecnológica são um diferencial e um recurso potencial para a transformação no modo de agir e pensar de professores e alunos? A resposta é sim. Foi possível confirmar por meio da pesquisa, das visitas, entrevistas colhidas e da análise dos documentos apresentados.

Podemos afirmar, ao analisar o material da rede, com base nas leituras e estudos feitos sob a luz da literatura, da dinâmica de sala de aula, do laboratório de informática e laboratório de ciência e tecnologia de uma escola da rede SESI e mais, ao entrevistar as profissionais responsáveis pelas aulas de Vivência Tecnológica, que os recursos utilizados, aliado à capacidade das profissionais e ao planejamento de aula, se apresentam como um recurso didaticamente estimulante, concreto e com possibilidades infinitas de interação com o conteúdo escolar.

$\mathrm{Na}$ prática da rede, as duas profissionais desempenham papéis distintos e complementares entre si, desta forma entendemos que cada profissional contribui de forma peculiar para as atividades de VT, o que nas observações realizadas e depoimentos colhidos, se mostrou bastante profícuo. Contudo, este trabalho tenta contribuir para que o processo de lógica do pensamento tecnológico se estenda também à alfabetização tecnológica dos professores.

Compreendemos como alfabetização tecnológica de professores habilidades de reconhecer nos recursos de informática potencial para desenvolver de forma diferente a abordagem do conteúdo. A avaliação do conhecimento discente, estratégia para a organização das disciplinas, repensar o espaço da sala de aula e uso de laboratórios, contemplando assim, não o uso do produto tecnológico em si (computadores, tablets, 
softwares, celulares), necessário para se implementar um conhecimento lógico, mas o mais importante, que é entender como estas tecnologias podem auxiliá-los no processo de ensino e aprendizagem (BELLONI, 2009).

Com base no conhecimento adquirido e desenvolvido com o trabalho com as tecnologias, o professor se apropria do conhecimento que estes recursos podem proporcionar, e intenta aplicá-los em várias circunstâncias como metodologia e estratégia, mostrando-se bastante eficaz no que diz respeito à formação continuada de professores.

Entendendo que a alfabetização, o letramento, suas múltiplas aplicações (matemático, digital, linguístico e outras) e o uso dos recursos tecnológicos são um conjunto intencional de acões, especialmente elaboradas para atingir um fim último de ensinar a ler e escrever no contexto social. E, ainda, de acordo com esta pesquisa, formar alunos com posicionamento crítico sobre as coisas do mundo, e favorecer interações que coloque os discentes como protagonistas do processo de ensino e aprendizagem, aqui entendido como proporcionar um ambiente e promover mediações onde os alunos participem ativamente do processo.

Verificamos que ao proporcionar as aulas de Vivência Tecnológica busca-se dar um contexto de uso real e palpável de produtos e serviços que o homem foi capaz de criar e desenvolver, ou seja, objetiva-se simular a vida de forma didática e contextualizada. É fato que os recursos tecnológicos não garantem a aprendizagem, contudo, verificamos que é possível diversificar as técnicas e métodos de ensino.

\section{REFERÊNCIAS}

BELLONI, M. L. Mídia-Educação: conceitos, história e perspectiva. Educ.

Soc.Campinas, vol. 30, n. 109, p. 1081-1102, set./dez. 2009.

KLEIMAN, A. B. Modelos de letramento e as práticas de alfabetização na escola. In: KLEIMAN, A. B. Os significados do letramento. Campinas/SP: Mercado das Letras, 2012.

LÉVY, P. As tecnologias da inteligência: o futuro do pensamento na era da informática. Tradução de Carlos Irineu da Costa. São Paulo: Ed. 34, 1993.

LUCAS, G. Vivências tecnológicas: Uma estratégia organizacional para auxiliar o processo de ensino e aprendizagem. 2015. 200 f. Dissertação (Mestrado em Educação) UFSCar, São Carlos. 2015. 
LUDKE, H. A., André, M. E.D.A. Pesquisas em educação: abordagens qualitativas. São Paulo: EPU, 2012.

MONTEIRO, M. I. Alfabetização e letramento na fase inicial da escolarização. São Carlos: EdUfscar, 2010.

PAPERT, S. A máquina das crianças: repensando a escola na era da informática. Porto Alegre: Artmed, 2008.

SAMPAIO, M. N.; LEITE, L. S. Alfabetização tecnológica do professor. Ed. Petrópolis, RJ: Vozes, 2010.

SESI/SP. Regimento interno do sistema escolar. São Paulo: SESI-SP, 2010a.

SESI/SP. Linguagens e códigos: língua portuguesa, arte e educação física: movimento do aprender: 1 ano, Ensino Fundamental. São Paulo: SESI, 2010c. 202p.

SESI/SP. Diretrizes para educação integral em tempo integral. São Paulo: SESI, 2013.

SESI/SP. Educação integral em tempo integral: sistematização de ações educativas. São Paulo: SESI, 2010 b.

SESI/SP. Referenciais Curriculares da Rede Escolar SESI-SP. Introdução ao fazer pedagógico da rede escolar SESI-SP. São Paulo: SESI, 2003. 2v.

SOARES, M. B. As muitas facetas da alfabetização. In: Alfabetização e letramento. São Paulo: Contexto, 2007.

\section{Como referenciar este artigo}

LUCAS, Giseli S.; MONTEIRO, Maria Iolanda. Planejamento em escolas públicas brasileiras na perspectiva de uma gestão escolar interdependente. Revista on line de Política e Gestão Educacional, Araraquara, v.21, n.3, p. 1388-1404, set./dez. 2017. ISSN: 1519-9029.

Submetido em: 10/07/2017

Aprovado em: 26/12/2017 